\title{
Virtual colonoscopy in stenosing colorectal cancer
}

\author{
Marco Coccetta ${ }^{\dagger}$, Carla Migliaccio ${ }^{\dagger}$, Francesco La Mura ${ }^{\dagger}$, Eriberto Farinella ${ }^{\dagger}$, \\ Ioanna Galanou ${ }^{\dagger}$, Pamela Delmonaco ${ }^{\dagger}$, Alessandro Spizzirri ${ }^{\dagger}$, \\ Vincenzo Napolitano ${ }^{\dagger}$, Lorenzo Cattorini ${ }^{\dagger}$, Diego Milani $^{\dagger}$, \\ Roberto Cirocchi* $^{*}$ and Francesco Sciannameo ${ }^{\dagger}$
}

Address: Department of General Surgical, St Maria Hospital, Terni, University of Perugia, Perugia, Italy

Email: Marco Coccetta - marcococce@libero.it; Carla Migliaccio - carlamigliaccio@gmail.com; Francesco La Mura - ciccioblacky81@yahoo.it; Eriberto Farinella - eriberto.far@gmail.com; Ioanna Galanou - ioanna.ga@libero.it; Pamela Delmonaco - pamela.delmonaco@alice.it; Alessandro Spizzirri - aspizzirri@libero.it; Vincenzo Napolitano - vnapolitano@yahoo.it; Lorenzo Cattorini - cremesys@excite.it; Diego Milani - milanidi@tiscali.it; Roberto Cirocchi* - cirocchiroberto@yahoo.it; Francesco Sciannameo - francescosciannameo@unipg.it

* Corresponding author †Equal contributors

Published: 9 November 2009

Annals of Surgical Innovation and Research 2009, 3:1I doi:10.1186/1750-1164-3-1I
Received: 4 January 2009

Accepted: 9 November 2009

This article is available from: http://www.asir-journal.com/content/3/I/II

(C) 2009 Coccetta et al; licensee BioMed Central Ltd.

This is an Open Access article distributed under the terms of the Creative Commons Attribution License (http://creativecommons.org/licenses/by/2.0), which permits unrestricted use, distribution, and reproduction in any medium, provided the original work is properly cited.

\begin{abstract}
Background: Between 5 and $10 \%$ of the patients undergoing a colonoscopy cannot have a complete procedure mainly due to stenosing neoplastic lesion of rectum or distal colon. Nevertheless the elective surgical treatment concerning the stenosis is to be performed after the pre-operative assessment of the colonic segments upstream the cancer.

The aim of this study is to illustrate our experience with the Computed Tomographic Colonography (CTC) for the pre-operative assessment of the entire colon in the patients with stenosing colorectal cancers.

Methods: From January 2005 till March 2009, we observed and treated surgically 43 patients with stenosing colorectal neoplastic lesions. All patients did not tolerate the pre-operative colonoscopy. For this reason they underwent a pre-operative CTC in order to have a complete assessment of the entire colon. All patients underwent a follow-up colonoscopy 3 months after the surgical treatment. The CTC results were compared with both macroscopic examination of the specimen and the follow-up coloscopy.

Results: The pre-operative CTC showed four synchronous lesions in four patients $(9.3 \%$ of the cases). The macroscopic examination of the specimen revealed three small sessile polyps ( 3 - $4 \mathrm{~mm}$ in diameter) missed in the pre-operative assessment near the stenosing colorectal cancer. The follow-up colonoscopy showed four additional sessile polyps with a diameter between $3-11 \mathrm{~mm}$ in three patients.

Our experience shows that CTC has a sensitivity of $83,7 \%$.

Conclusion: In patients with stenosing colonic lesions, CTC allows to assess the entire colon preoperatively avoiding the need of an intraoperative colonoscopy. More synchronous lesions are detected and treated at the time of the elective surgery for the stenosing cancer avoiding further surgery later on.
\end{abstract}




\section{Background}

The patients suffering from stenosing colorectal cancer are frequently treated for occlusion $(20 \%)$ and stenosis $(16 \%)$ [1]. The elective surgical treatment concerning the stenosis is to be performed after the preoperative assessment of the colonic segments upstream the cancer.

If the endoscopic instrument can pass over the lesion, the gold standard is the colonoscopy. On the other hand, when the instrument cannot surmount the stenosis, the proximal segment of colon is to be evaluated through a double contrast barium enema. This approach shows low sensitivity and specificity particularly in the right colon [2].

Threfore when barium enema does not lead to an accurate evaluation, the patient needs an intra-operatory colonoscopy [3]. This investigation implies a few difficulties as the patient needs to be positioned on the operating table. It also requires additional time and can make the abdominal closure more difficult, because of the bowel distension caused by the insufflated air $[4,5]$.

When the endoscopic procedure is incomplete because of the presence of a severe stenosing lesion, a further colonoscopy is required at 3-month follow up [6,7], in order to rule out a missed synchronous lesions.

The recent introduction of CTC allows a more adequate preoperative assessment of colon showing higher sensitivity and specificity [8]. The aim of this study is to illustrate our experience with the CTC for the pre-operative assessment of the entire colon in the patients with stenosing colorectal cancer.

\section{Methods}

From January 2005 till March 2009, we observed and treated 43 patients with stenosing colorectal neoplastic lesions presenting with changes in the bowel habit, constipation, abdominal pain and lower gastrointestinal bleeding. We observed 28 males and 15 females aged between 47 and 73 years (average age 65 years). All patients did not tolerate the endoscopic procedure. For this reason they underwent a CTC in order to have a complete pre-operative assessment of the entire colon. All 43 patients underwent a pre-operative CTC in order to have a complete assessment of the entire colon. All 43 patients underwent surgical resections and specimen was carefully evaluated to search for any synchronous lesions. Furthermore all patients underwent a follow-up colonoscopy at 3 months from surgery.

The results from CTC were compared with both macroscopic examination of specimen and the follow-up colonscopy.

\section{Results}

The CTC showed synchronous lesions in 4 patients $(9.3 \%$ of the cases) (Table 1):

- a pedunculated polyp in two cases (8 and $12 \mathrm{~mm}$ of diameter) both in the left colon;

- a sessile polyp (18 $\mathrm{mm}$ of diameter) in ascending colon;

- a voluminous vegetating lesion (36 $\mathrm{mm}$ of diameter) in the ascending colon.

The patients with synchronous colonic lesions are usually treated through a laparotomic access, as identifying laparoscopically synchronous lesions without a tattoo marked preoperatively is difficult.

Furthermore, often it is not possible to identify synchronous lesions by intra-operative palpation even if the diameter is larger than one centimetre $[9,10]$. This supports the need of good preoperative assessment.

In our series the patients with synchronous neoplastic lesions underwent the following surgical treatments (Table 1):

Table I: Stenosing colorectal cancer and synchronous lesions showed in the pre-operative CTC

\begin{tabular}{|c|c|c|c|c|}
\hline $\begin{array}{l}\text { Site of stenosing } \\
\text { colorectal cancer }\end{array}$ & $\begin{array}{l}\text { Synchronous lesions } \\
\text { Site }\end{array}$ & $\begin{array}{l}\text { Synchronous lesion } \\
\text { Type }\end{array}$ & $\begin{array}{l}\text { Diameter of } \\
\text { synchronous lesions }\end{array}$ & Surgical Treatment \\
\hline Sigmoid colon & Descending colon & Pedunculated polyp & $8 \mathrm{~mm}$ & $\begin{array}{l}\text { Left laparoscopic } \\
\text { hemicolectomy }\end{array}$ \\
\hline Rectum & Ascending colon & Pedunculated polyp & $12 \mathrm{~mm}$ & $\begin{array}{l}\text { Laparoscopic anterior } \\
\text { resection of rectum }\end{array}$ \\
\hline Sigmoid colon & Ascending colon & Sessile polyp & $18 \mathrm{~mm}$ & $\begin{array}{l}\text { Left laparotomic } \\
\text { hemicolectomy and } \\
\text { excision of polyp through } \\
\text { enterotomy }\end{array}$ \\
\hline Descending colon & Ascending colon & $\begin{array}{l}\text { Voluminous vegetating } \\
\text { cancer }\end{array}$ & $36 \mathrm{~mm}$ & $\begin{array}{l}\text { Subtotal laparotomic } \\
\text { colectomy }\end{array}$ \\
\hline
\end{tabular}


Table 2: Stenosing colorectal cancers and synchronous lesionsidentified specimen and missed in the pre-operative CTC.

\begin{tabular}{llll}
\hline Site of stenosing colorectal cancer & Site of synchronous lesion & Type of synchronous lesions & Diameter of synchronous lesions \\
\hline Left colon & Left colon & Sessile polyp & $3 \mathrm{~mm}$ \\
Left colon & Left colon & Sessile polyp & $4 \mathrm{~mm}$ \\
Left colon & Left colon & Sessile polyp & $3 \mathrm{~mm}$ \\
\hline
\end{tabular}

- Left laparoscopic hemicolectomy (stenosing sigmoid cancer with adjacent peduncalated polyp of descending colon)

- Laparoscopic anterior resection of rectum (stenosing rectal cancer with adjacent peduncalated polyp of sigmoid colon).

- Left laparotomic hemicolectomy associated with excision of polyp through enterotomy in the ascending colon (stenosing cancer of sigmoid colon associated a sessile polyp of ascending colon).

- Subtotal laparotomic colectomy for two synchronous neoplastic lesions located in distant colic segments (descending colon stenosing cancer associated with vegetant neoplastic lesion of ascending colon).

\section{Table I}

The macroscopic examination of the specimen revealed three patients with small sessile polyps (3 - $4 \mathrm{~mm}$ in diameter) missed in the pre-operative CTC near the stenosing colorectal cancer (Table 2).

\section{Table 2}

The follow-up colonscopy showed four additional endoluminal lesions in three patients: four sessile polyps with diameter of 3, 4, 8 and $11 \mathrm{~mm}$ (Table 3)

\section{Table 3}

Our experience shows that virtual colonoscopy has a sensitivity of $83,7 \%$.

\section{Discussion}

Computed Tomographic Colonography (CTC) is also known as "virtual colonoscopy" and it was introduced in 1994. It is considered a noninvasive method of imaging and it allows to explore the colon by employing a helical CT [11].

Data from literature show that CTC is safer than colonoscopy. Indeed a colonic perforation occurs in 1:1000 patients undergoing conventional colonoscopy and mortality associated with this procedure is 1:5000 [12-17], while the morbidity and mortality associated with CTC are similar to those of the air-contrast barium enema (perforation rate of 1:10000 and mortality rate of 1:50000) [18-20].

There is only one study in literature showing a perforation rate, which is very low, up to $0.04 \%(3 / 7180)$ [21] and no study showing a case of death after performing a CTC.

The CTC has recently been proposed as the standard investigation for the pre-operative assessment of the colonic segments proximal to the obstructive cancer, being well tolerated, less invasive and showing good results [4,22-25].

Usually the colonoscopy is not fully carried out up to the ileocecal valve in $5-10 \%$ of the patients; this is mainly due to [26]:

- presence of stenosing neoplastic lesion of rectum or distal colon $(58,3 \%)$ :

- presence of dolicocolon (33\%);

- presence of spastic colon $(11,7 \%)$.

- presence of extrinsic compressions $(1,6 \%)$;

- presence of intestinal malrotation $(1,6 \%)$;

Table 3: Stenosing colorectal cancers and synchronous lesions identified in the follow-up colonoscopy at 3 months after the surgical treatment and missed in the pre-operative CTC

\begin{tabular}{llll}
\hline Site of stenosing colorectal cancer & Site of synchronous lesion & Type of synchronous lesions & Diameter of synchronous lesions \\
\hline Left colon & Ascending colon & Sessile polyp & $3 \mathrm{~mm}$ \\
Left colon & Transverse colon & Sessile polyp & $4 \mathrm{~mm}$ \\
Left colon & Transverse colon & Sessile polyp & $8 \mathrm{~mm}$ \\
Rectum & Left colon & Sessile polyp & $11 \mathrm{~mm}$ \\
\hline
\end{tabular}


Table 4: Virtual colonoscopy in stenosing colorectal cancers: sensitivity for synchronous lesions after colonoscopy follow-up at 3 months

\begin{tabular}{|c|c|c|c|c|c|}
\hline & & $\begin{array}{l}\text { Preoperative evaluation of the colon } \\
\text { proximal to the obstructive } \\
\text { colorectal cancer }\end{array}$ & $\begin{array}{l}\text { Pts. with colorectal cancers } \\
\text { and obstructing colorectal } \\
\text { lesions }\end{array}$ & $\begin{array}{l}\text { Lesions missing at } \\
\text { preoperative virtual } \\
\text { colonoscopy }\end{array}$ & Sensitivity \\
\hline Fenlon & 1999 & СТС & 12 pts. & 2 & $83.4 \%$ \\
\hline Galia & 2001 & СТС & 19 pts. & 3 & $83.4 \%$ \\
\hline Morrin & 2005 & СТС & 17 pts & 1 & $93 \%$ \\
\hline Nagata & 2009 & PET/CT colonography & 13 pts. & 0 & $100 \%$ \\
\hline
\end{tabular}

- presence of visceral adhesions.

In the past in all these cases the alternative investigation was an opaque enema. Nowadays, CTC shows a higher sensitivity making it the choice investigation when the traditional endoscopy cannot be carried out satisfactorily [26].

All CTCs performed in the above mentioned cases were successful $(91,7-100 \%)$ (table 4) $[4,22,23,27]$.

\section{Table 4}

The cause of failure is frequently based either on neoplastic obstruction or on an inadequate air distension of proximal colon $(8,3 \%)$ [26].

Data from literature show that CTC allows the diagnosis of synchronous lesions in $27,2 \%-89,6 \%$ of cases [28]. CTC substantially owns the same sensitivity as an optical colonoscopy for polyps $>$ or $=7 \mathrm{~mm}$ in diameter [29]. Most of the polyps were observed in ascending colon $(31,25 \%)$, transverse colon $(18,75 \%)$, descending colon $(18,75 \%)$ and sigma $(6,25 \%)[26]$. The diameter of the polyps varies between $5 \mathrm{~mm}(25 \%), 6-9 \mathrm{~mm}(62,5 \%)$ and $10 \mathrm{~mm}(12,5 \%)$ [26]. Between $6.25 \%$ and $8.3 \%$ of the observed synchronous lesions resulted to be cancers $[22,26]$.

In those patients with synchronous cancers the most appropriate approach is to remove both lesions at the same time. Fenlon et al. described a subtotal colectomy for sigmoid and trasverse colon cancers and a left hemicolectomy for spleen flexure and sigma lesion [22].

Mingyue et al stated in their study that although the synchronous lesion is a polyp, it should be removed during surgery, otherwise, in the remaining cases, polyps will be removed during the endoscopic follow-up [26].

In the past, a considerable percentage of CTC presented a high incidence of false positives (between $54.6 \%$ and $64 \%$ for polyps within $6-10 \mathrm{~mm}$ of diameter, and $41-51 \%$ for polyps larger than $10 \mathrm{~mm}$ in diameter) $[10,30,31]$.
Nowadays more modern softwares and new methods for colon cleansing preparation allow a significant reduction of false positives [32], lowering the percentage till 2.1\% for polyps and $0.7 \%$ for cancers [33] despite the first results appeared in literature [34-36].

Moreover the possibility to perform the CTC even with a mild bowel preparation allows to extend the indication of the cancer screening to those patients considered not enough fit to tolerate a complete bowel preparation [37].

An accurate evaluation of the colonic segments upstream the neoplastic obstruction is extremely important as the patients with colorectal cancer are often affected by synchronous neoplastic lesions (villous adenomas in 33-55\% of the cases and other types of cancers in 3\% of the cases) $[36,38,39]$ (figures $1,2,3,4)$. A surgical re-intervention is required when synchronous neoplastic lesions are detected and this increases morbidity and higher complication rates, especially because of peritoneal adhesions.

In case of synchronous lesions the prognosis becomes worse than a single cancer (55\% survival at 5 years) [40], especially when diagnosis and treatment are not carried out on time.
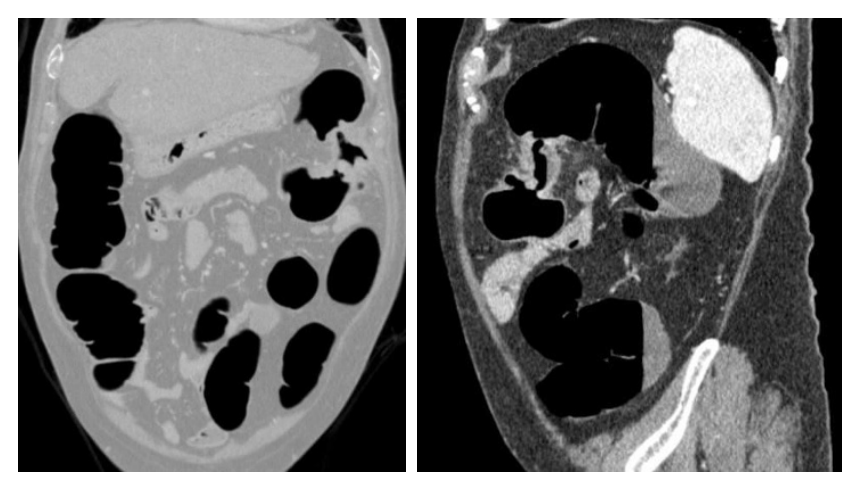

Figure I

Cancer of splenic flexure unsurpassed by colonoscopy. 

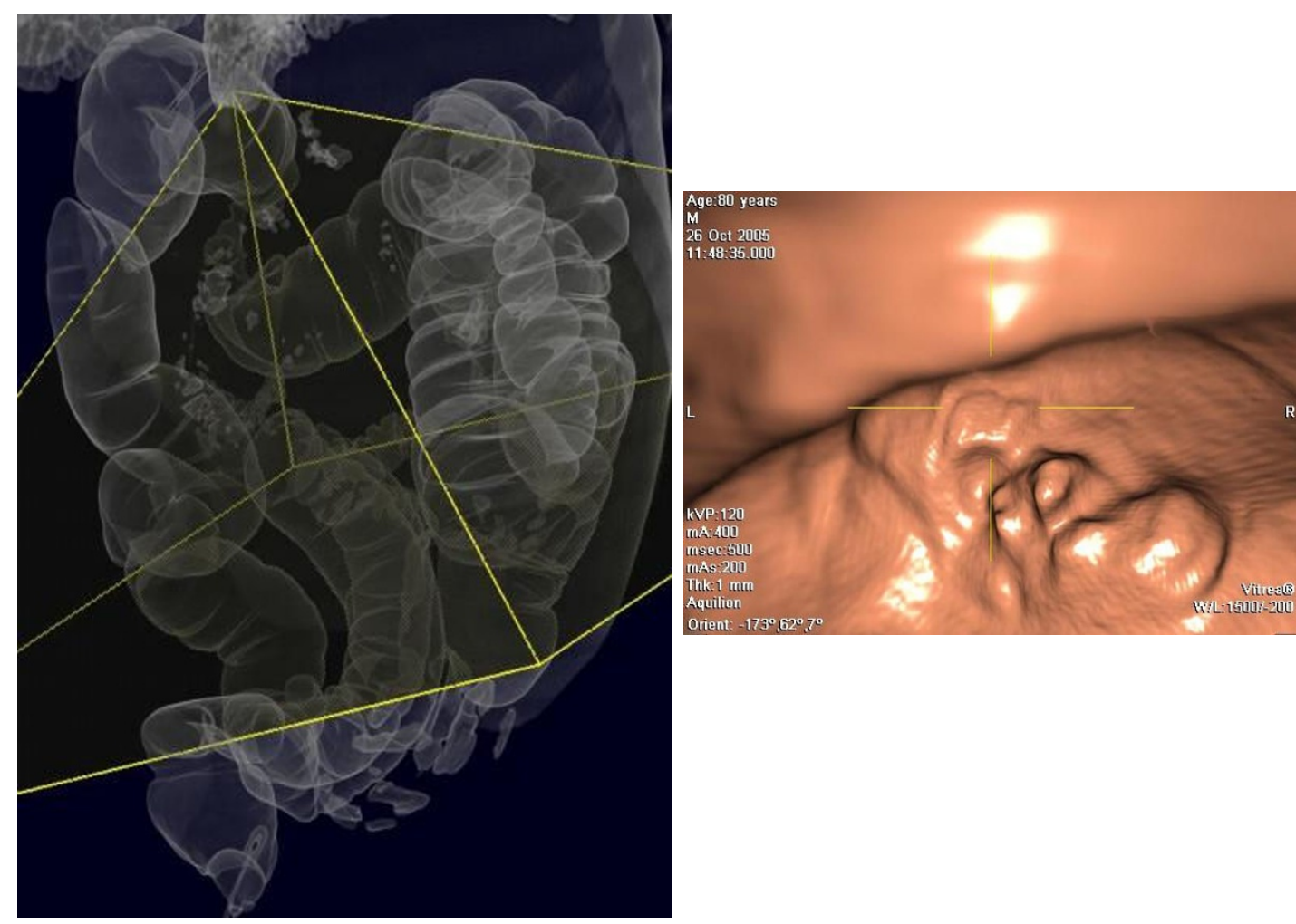

Figure 2 3D Reconstruction with iconographic effect similar to double contrast barium enema of splenic flexure's cancer.
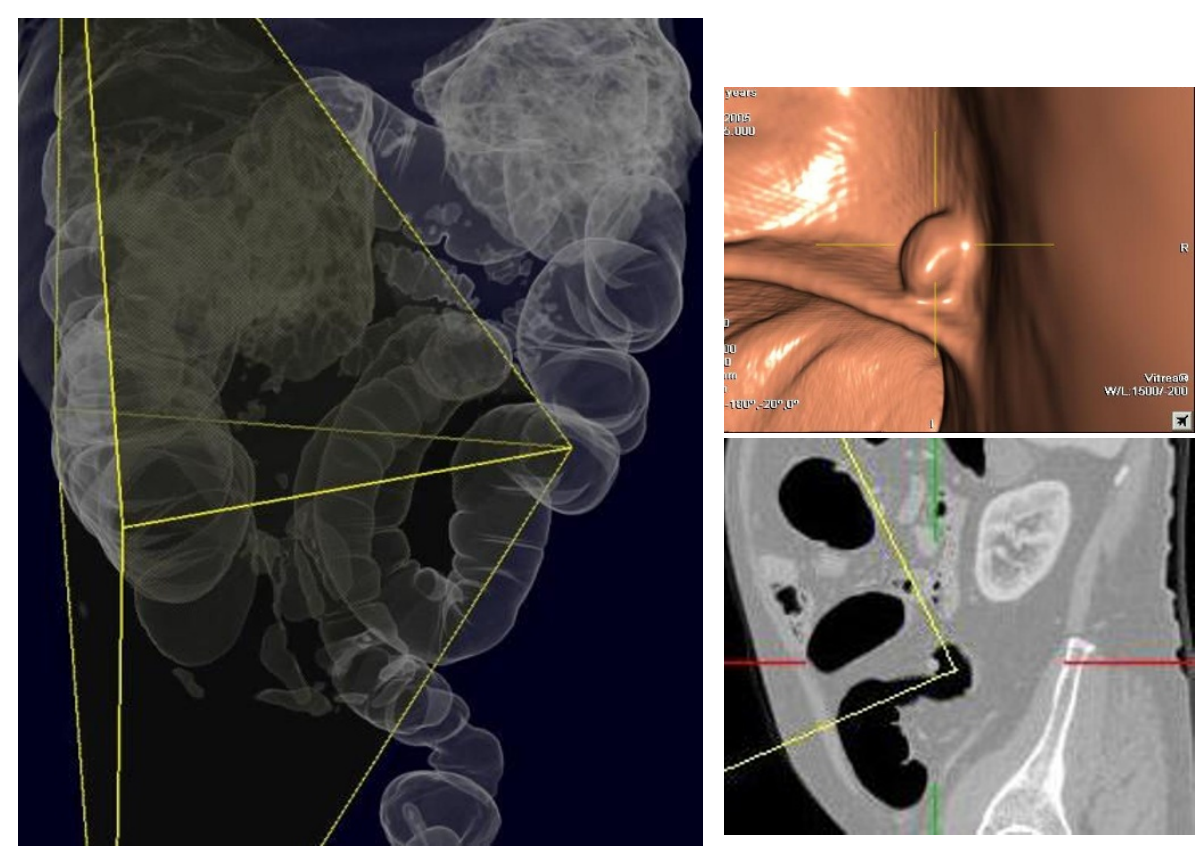

Figure 3

Downstream polyp of splenic flexure cancer's. 

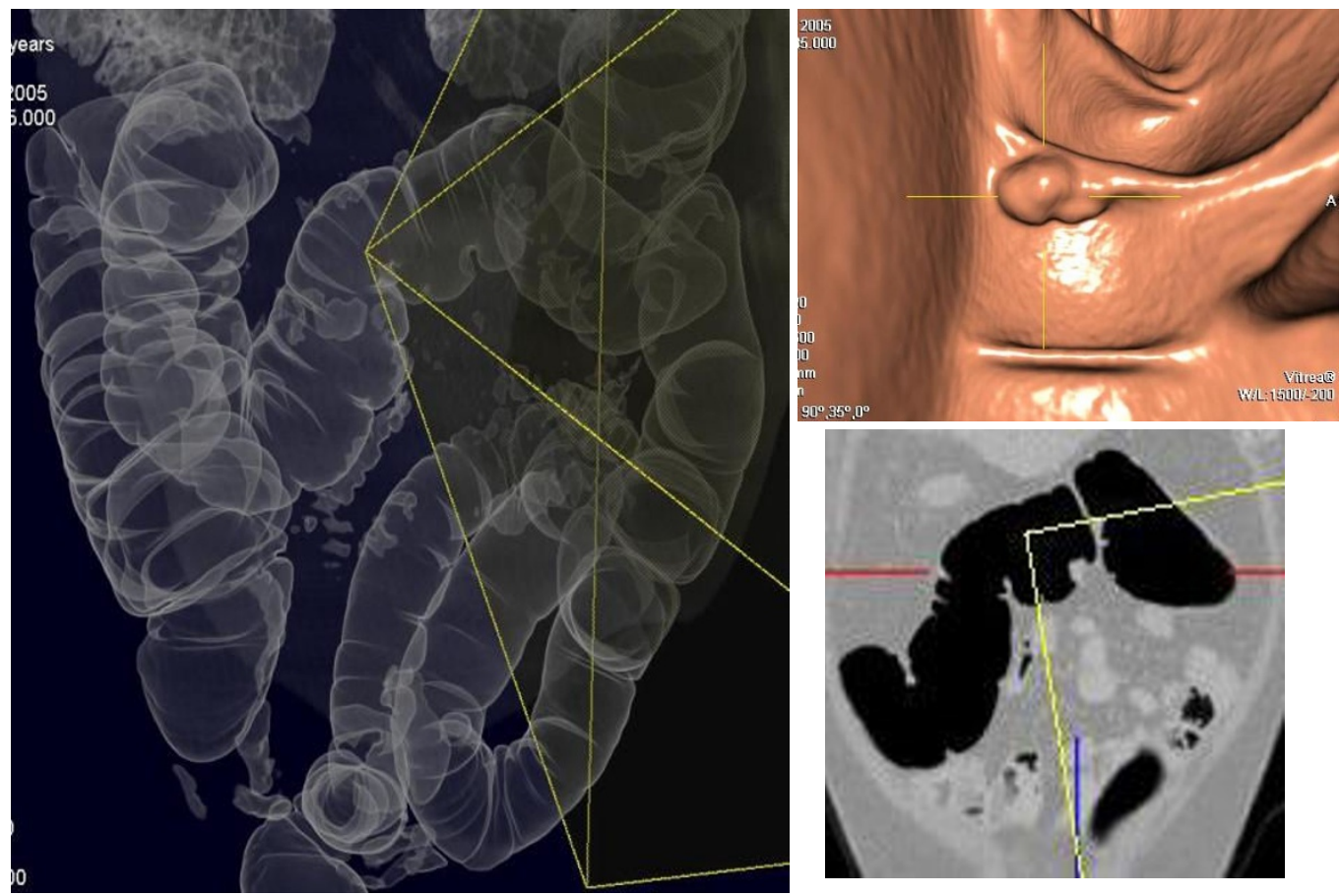

Figure 4

Upstream polyp of splenic flexure cancer's.

Currently CTC is very helpful in colorectal surgery and it is particularly useful during the preoperative study in laparoscopic colorectal surgery; an accurate localization of the lesions not only allows an appropriate trocar insertion, but it also reduces the error due to a lack of tactile sensation [41].

It can be difficult to find out whether synchronous colon cancers are present in an intestinal segment proximal to the obstructive cancer. These patients usually need a further sequent surgical treatment if synchronous colon cancers are detected later [42]. An accurate diagnosis including the evaluation of the colonic segments proximal to the obstruction can avoid additional surgical approaches providing a better quality of life, as well as being cost-effective [9,43-45]. Therefore, one of the important roles of preoperative diagnosis in patients with obstructive cancer is a precise evaluation of the entire colon [4].

\section{Conclusion}

This study shows CTC as a valid pre-operative investigation (sensitivity $83.7 \%$ ) in order to detect synchronous neoplastic lesions in the patients who do not tolerate the conventional colonoscopy because of stenosing colorectal cancer. The main benefits from from its employment are that the intraoperative colonoscopy is not needed and more synchronous lesions are detected and treated at the time of the elective surgery for the stenosing cancer avoiding further surgery later on.

\section{Competing interests}

The Authors state that none of the authors involved in the manuscript preparation has any conflicts of interest towards the manuscript itself, neither financial nor moral conflicts. Besides none of the authors received support in the form of grants, equipment, and/or pharmaceutical items.

\section{Authors' contributions}

All authors contributed equally to this work.

\section{Consent}

Written informed consent was obtained from the patient for publication of this case report and accompanying images. A copy of the written consent is available for review by the Editor-in-Chief of this journal.

\section{Acknowledgements}

The authors give thanks to Dr Francesco Mancioli, Department of Radiology, St Mary Hospital for the offered photos.

\section{References}

I. Simmang CL, Huber PJ: Management of cancer of the colon. In Fazio VW, Church JM, Delaney CP Editors. Current therapy 
in colon and rectal surgery. Elsevier Mosby, Philadelphia 2004:379-94.

2. Loose HW, Williams CB: Barium enema versus colonscopy. Proc Roy Soc Med 1974, 67: 1033.

3. Cohen JK, Forde KA: Intraoperative colonscopy. Ann Surg 1988, 207:231-3.

4. Nagata K, Ota Y, Okawa T, Endo S, Kudo S: PET/CT Colonography for the Preoperative Evaluation of the Colon Proximal to the Obstructive Colorectal Cancer. Dis Colon Rectum 2008, $51: 882-890$

5. Tate JJ, Rawlinson J, Royle GT, Brunton FJ, Taylor I: Preoperative or postoperative colonic examination for synchronous lesions in colorectal cancer. $\mathrm{Br} J$ Surg 1988, 75:1016-8.

6. Senagore AJ: Post-operative follow up of rectal cancer. In Clinical decision making in colorectal surgery Edited by: Wexner SD, Vernava III AM. Igaku-Shoin, New York; 1995:255-7.

7. Luchtefeld MA: Post-operative follow up of colon cancer. In Clinical decision making in colorectal surgery Edited by: Wexner SD, Vernava III AM. Igaku-Shoin, New York; 1995:385-7.

8. Johnson $C D$, Hara AK, Reed JE: Computed tomographic colonography (virtual colonoscopy). A new metod for detecting colorectal neoplasms. Endoscopy 1997, 29:454-6I.

9. Bat L, Neumann G, Shemesh E: Association of synchronous neoplasms with occluding colorectal cancer. Dis Colon Rectum 1985, 28:|49-5|.

10. Pickhardt PJ, Choi JR, Hwang I, Bunder JA, Puckett ML, Hildebrandt HA: Computed tomography virtual colonscopy to screen for rectal for rectal neoplasia in asymptomatic adults. N Engl Med 2003, 349:219|-200.

II. Vining DJ, Gelfand DW: Noninvasive colonoscopy using helical CT scanning, ED reconstruction, and virtual reality. Presented at the 23rd Annual Meeting and Postgraduate Course of the Society of Gastrointestinal Radiologists, Maui, HI 1994.

12. Habr-Gama A, Waye JD: Complications and hazards of gastrointestinal endoscopy. World J Surg 1989, 13:193-201.

13. Winawer SJ, Fletcher RH, Miller I, Godlee F, Stolar MH, Mulrow CD, Woolf SH, Glick SN, Ganiats TG, Bond JH, Rosen L, Zapka JG, Olsen SJ, Giardiello FM, Sisk JE, Van Antwerp R, Brown-Davis C, Marcianiak DA, Mayer RJ: Colorectal cancer screening: clinical guidelines and rationale. Gastroenterology 1997, I | 2:594-642.

14. Rex DK, Lehman GA, Hawes RH, Ulbright TM, Smith J): Screening colonoscopy in symptomatic average-risk persons with negative fecal occult blood tests. Gastroenterology 1991, 100:64-7.

15. Godreau C): Office-based colonoscopy in a family practice. Fam Pract Res J 1992, 1 2:313-20.

16. Jentschura D, Raute M, Winter J, Henkel T, Manegold BC: Complications in endoscopy of the lower gastrointestinal tract: therapy and prognosis. Surg Endosc 1994, 8:672-6.

17. Waye JD, Lewis BS, Yessayan S: Colonoscopy: a prospective report of complications. / Clin Gastroenterol 1992, I 5:347-5 I.

18. Masel H, Masel JP, Casey KV: A survey of colon examination techniques in Australia and New Zealand with a review of complications. Australas Radiol I97I, I 5:|40-7.

19. Gardiner H, Miller RE: Barium peritonitis: a new therapeutic approach. Am J Surg 1973, I 25:350-2.

20. Han SY, Tishler JM: Perforation of the colon above the peritoneal reflection during the barium-enema examination. Radiology 1982, 144:253-5.

21. Bar-Meir E, Amitai M, Blachar A, Peled N, Bar-Ziv ]: Assessment of the risk of perforation at CT colongraphy. Presented at the 90th Scientific Assembly and Annual Meeting of Radiological Society of North America, Chicago, IL 2004.

22. Fenlon HM, McAnemy DB, Nunes DP, Clarke PD, Ferrucci JT: Occlusive colon carcinoma: virtual colonscopy in the preoperative evaluation of the proximal colon. Radiol 1999, 21 0:423-8.

23. Morrin MM, Farrell RJ, Raptopoulos V, McGee JB, Bleday R, Kruskal $\mathrm{JB}$ : Role of virtual computed tomographic colonography in patients with colorectal cancers and obstructing colorectal cancers and obstructing colorectal lesions. Dis Colon Rectum 2000, 43:303-II.

24. Neri E, Giusti P, Battolla L, Vagli P, Boraschi P, Lencioni R, Caramella $D$, Bartolozzi C: Colorectal cancer: role of $C T$ colonography in preoperative evaluation after incomplete colonoscopy. Radiology 2002, 223:615-9.
25. Copel L, Sosna J, Kruskal JB, Raptopoulos V, Farrell RJ, Morrin MM: CT colonography in 546 patients with incomplete colonoscopy. Radiology 2007, 244:47I-8.

26. Mingyue L, Hong S, Kangrong Z: CT virtual colonscopy in patients with incomplete conventional colonscopy. CMJ 2002, 155:1023-6.

27. Galia M, Midiri M, Carcione A, Cusmà S, Bartolotta TV, Angileri T, De Maria M, Lagalla R: Usefulness of CT colonography in the preoperative evaluation of patients with distal occlusive colorectal carcinoma. Radiol Med 200I, I 0 I(4):235-42.

28. Bonelli: Colorectal carcinoma: is screening possible? Tech Coloproctol 2004, 8(Suppl 2):s267-72.

29. Menardo G: Sensitivity of diagnostic examinations for colorectal polyps. Tech Coloproctol 2004, 8(Suppl 2):s273-5.

30. Hwang I: Limitations of virtual colonscopy. Ann Internal Medicine 2005, 142:155-6.

31. Van Gelder RE, Nio CY, Floric J, Bartelsman JF, Snel P, De Jager SW: Computed tomography colonography compared with colonscopy in patients at increased risk for colorectal cancer. Gastroenterol 2004, 127:4|-8.

32. Pickhardt PJ: Differential diagnosis of polypoid lesions seen on CT colonography (virtual colonscopy). Radiograph 2004, 24:1535-56.

33. Summers R, Yao J, Pickhardt PJ, Franaszek M, Bitter I, Brickman D, Krishna V, Choi R: Computed tomography virtual colonoscopy computer-aided polyp detection in a screening population. Gastroenterol 2005, 129:1832-44.

34. Miao YM, Amin Z, Healey J, Burn P, Murugan N, Westaby D, AllenMersh TG: A prospective single centre study comparing computed tomography pneumocolon against colonscopy in the detection of colorectal neoplasms. Gut 2000, 47:832-7.

35. Pescatore P, Glucker T, Delarive J, Meuli R, Pantoflickova D, Duvoisin $B$, Schnyder P, Blum AL, Dorta G: Diagnostic accuracy and interobserver agreement of CT colongraphy (virtual colonscopy). Gut 2000, 47:126-30

36. Phillips RKS: Rectal cancer. In Colorectal Surgery Edited by: Phillips RKS. Elsevier Saunders, Philadelphia; 2005:67-82

37. Taylor SA, Slater A, Burling DN, Tam E, Greenhalgh R, Gartner L, Scarth J, Pearce R, Bassett P, Halligan S: CT colonography: optimization, diagnostic performance and patient acceptability of reducted-laxative regimens using barium-based faecal tagging. Eur Radiol 2008, 18:32-42.

38. Corman ML: Carcinoma of the rectum. In Colon \& Rectal Surgery Edited by: Corman ML. Lippincott-Raven, Philadelphia; 1998:733-862.

39. Thorson AG, Christensen MA, Davis SJ: The role of colonoscopy in the assessment of patients with colorectal cancer. Dis Colon Rectum 1986, 29:306-II.

40. Moreaux J, Catala M: Multiple cancers of the colon and rectum. Incidence and results of surgical treatment. Gastroenterol Clin Biol 1985, 9:336-4I.

4I. Baka B, Selcuk D, Erenler Kilic I, Erdamar S, Salihoglu Z, Hamzaoglu I, Karahasanoglu $T$ : The contributions of virtual colonoscopy to laparoscopic colorectal surgery. Hepato-Gastroenterology 2007, 54:1976-1982.

42. McDermott JP, Devereaux DA, Caushaj PF: Pitfall of laparoscopic colectomy: an unrecognized synchronous cancer. Dis Colon Rectum 1994, 37:602-3

43. Imperiale TF, Wagner DR, Lin CY, Larkin GN, Rogge JD, Ransohoff DF: Risk of advanced proximal neoplasms in asymptomatic adults according to the distal colorectal findings. N EnglJ Med 2000, 343:169-74.

44. Betes Ibanez M, Munoz-Navas MA, Duque JM, Angos R, Macias E, Subtil JC, Herraz M, de la Rive S, Delgado-Rodrigquez M, MartinezGonzalez MA: Diagnostic value of distal colonic polyps for prediction of advanced proximal neoplasia in an average-risk population undergoing screening colonoscopy. Gastrointest Endosc 2004, 59:634-4l.

45. Cirocchi R, Coccetta M, Giuliani D, Morelli U, Spizzirri A, Cattorini L, Mancioli F, Giustozzi G, Sciannameo F: Colonscopia virtuale nelle neoplasie stenosanti del colon-retto. Chir ltal 2008 , 60(2):233-236. 